\title{
Correction to: Novel observations in choroidal osteoma by multispectral imaging: a pilot case series
}

\author{
Feiyan Ma (ib) Tianhang Li • Igor Kozak $\cdot$ Jingxue Ma $\cdot$ Qingli Shang
}

Published online: 16 January 2021

(C) Springer Nature B.V. 2021

Correction to: Int Ophthalmol (2020) 40:3413-3430 https://doi.org/10.1007/s10792-020-01528-9

In the original publication, the order of authors has been published incorrectly. The correct order of authors is updated in this correction.
Publisher's Note Springer Nature remains neutral with regard to jurisdictional claims in published maps and institutional affiliations.

The original article can be found online at https:// doi.org/10.1007/s10792-020-01528-9.

F. Ma · T. Li · J. Ma $(\varangle) \cdot$ Q. Shang $(\varangle)$ Department of Ophthalmology, The Second Hospital of Hebei Medical University, Shijiazhaung 050000,

Hebei Province, China

e-mail: zhangjh_2019@163.com

Q. Shang

e-mail: qinglishang2013@sina.cn

I. Kozak

Moorfields Eye Hospitals UAE, Abu Dhabi, United Arab Emirates 